\title{
An analysis of the survival rate after radiotherapy in lung cancer patients with bone metastasis: Is there an optimal subgroup to be treated with high-dose radiation therapy?
}

\author{
T. KOMATSU*, E. KUNIEDA, Y. OIZUMI, Y. TAMAI, T. AKIBA \\ Department of Radiation Oncology, Tokai University School of Medicine, 143 Shimokasuya, Isehara, Kanagawa 259-1193, Japan \\ *Correspondence: komat@tokai-u.jp
}

Received March 18, 2012 / Accepted May 21, 2012

\begin{abstract}
We investigated the prognostic factors after radiotherapy for bone metastasis from lung cancer while taking the recent findings in the treatment of such cases into consideration. A total of 132 patients with bone metastases from pathologically confirmed lung cancer were evaluated regarding the following potential prognostic factors: treatment for primary site (surgery vs. other), treatment site (spine vs. other), number of bone metastases (solitary vs. multiple), number of metastatic organs (0 vs. 1 vs. $\geq 2$ ), neurological symptoms (no symptoms vs. numbness vs. paresis), degree of pain (no pain vs. mild pain vs. severe pain), performance status [PS] (0-1 vs. $\geq 2$ ), biological effective dose [BED] ( $\geq 40$ Gy vs. $<40$ Gy), time to distant metastasis ( $\geq 1$ year vs. $<1$ year), histology (adenocarcinoma vs. others), and use of epidermal growth factor receptor [EGFR]-targeted agents (Yes vs. No). The univariate analysis demonstrated that all factors except for the treatment site were significant. Surgery as treatment for primary site, solitary bone metastasis, no visceral organ metastasis, no symptoms or numbness, no pain, PS $<2$, $\mathrm{BED} \geq 40 \mathrm{~Gy}$, time to distant metastasis $\geq 1$ year, adenocarcinoma histology, and use of EGFR-targeted agents were correlated with a favorable prognosis.

In a multivariate analysis, solitary bone metastasis, $\mathrm{PS}<2, \mathrm{BED} \geq 40 \mathrm{~Gy}$, adenocarcinoma histology, and the use of EGFRtargeted agents were significantly correlated with a better survival $(p=0.038,0.006,0.003,0.014$, and $<0.001$, respectively). A contingency table to assess the relationship between each variable and the median survival time of the patients according to the administered BED showed that in patients with the time to distant metastasis $\geq 1$ year and the use of EGFR-targeted agents, the subgroups treated with $\mathrm{BED} \geq 40 \mathrm{~Gy}$ had a favorable prognosis. Our study suggests that high-dose radiotherapy is associated with a better prognosis in combination with other favorable prognostic factors
\end{abstract}

Key words: radiotherapy, bone metastases, survival, oligometastases, epidermal growth factor receptor [EGFR]-targeted agents, biological effective dose

Lung cancer is the leading cause of cancer death in the world, and the bone is one of the most common metastatic site. Bone metastasis occurs in 30-36\% of lung cancer patients, and $65 \%$ of these are detected at the time of initial staging $[1,2]$. Patients with lung cancer who develop bone metastasis have a poor prognosis; the median survival time [MST] ranges from7.2 to 7.9 months $[1,3]$. In addition, bone metastases produce considerable morbidity. In cases where surgery is performed as the initial treatment, the prognosis is also poor, as the MST is approximately 170 days, once bone metastasis occurs [4]. The major roles of radiotherapy are the relief of bone pain, prevention of pathological fracture, and/or improvement of neurological symptoms due to spinal cord compression. In Japan, $34.3 \%$ of patients with bone metastasis from lung cancer undergo radiotherapy aimed at maintaining or improving their quality of life [1].

Many clinical trials and meta-analyses to identify the optimal dose-fractionation schedule of radiotherapy for bone metastases have demonstrated the equivalence of different dose-fractionation schedules for the palliation of pain due to bone metastases, and a trend is toward giving a single fraction [5-8]. On the other hand, Rose et al. [9] stated that the dosefractionation schedule should be decided based on the patient's life expectancy. In Alysa's research [10], a single fraction was not commonly prescribed, and many clinicians gave priority to the life expectancy. Almost all of the past studies were reported 
on bone metastases from various cancers, and did not focus on lung cancer alone. The prognosis and response to radiotherapy are different among each primary site, so it is necessary to estimate the dose according to the primary site. Although the majority of bone metastases arise from primary tumors of the breast, prostate, or lungs, the prognosis and response to radiotherapy for bone metastasis from lung cancer are inferior to those of breast and prostate cancer $[2,5,6,8,11]$.

It has recently been reported that epidermal growth factor receptor [EGFR]-targeted agents improve the prognosis of lung cancer patients, so the role of radiotherapy in patients with bone metastasis from lung cancer may have changed [12-14].

Furthermore, the notion of oligometastases merits consideration when developing a new treatment strategy. Oligometastases indicate the presence of a limited number of metastases, and recent studies have revealed the effectiveness of radiotherapy for such lesions $[15,16]$. Nevertheless, the prognosis of lung cancer patients is still very poor, so whether the notion of oligometastases could be true of metastasis from lung cancer or not remains unclear.

For these reasons, we performed a retrospective study of the prognostic factors after radiotherapy in patients with bone metastasis from lung cancer to determine whether there is a subgroup of patients who should be treated with high-dose radiation therapy.

\section{Materials and methods}

Of the patients who underwent their first radiotherapy treatment for bone metastases at our institute from January 1 , 2004 to January 5, 2009, 132 patients met our study's eligibility criteria (patients with bone metastases from pathologically confirmed lung cancer who completed radiotherapy as planned). Institutional review board approval was obtained for this retrospective analysis. The diagnosis of bone metastasis was confirmed by computed tomography, magnetic resonance imaging, or bone scintigraphy. The patient characteristics are summarized in Table1. The median age was 63 years (range, 30-88 years). Ninety-one (69\%) patients were male and 41 (31\%) were female. Adenocarcinoma was the most frequently observed histologic subtype (68\%). There were 41 (31\%) patients with solitary bone metastasis and the remaining 91 (69\%) showed multiple bone metastases. Almost half of the patients had no coexisting distant metastasis. We investigated the cumulative overall survival rate after radiotherapy and the prognostic factors in patients with bone metastasis from lung cancer.

The following potential prognostic factors were evaluated. (subgroups are provided in parentheses): treatment for the primary site (surgery vs. other), bone metastases treatment site (spine vs. other), number of bone metastases (solitary vs. multiple), number of metastatic organs ( 0 vs. 1 vs. $\geq 2$ ), neurological symptoms (no symptoms vs. numbness vs. paresis), degree of pain (no pain vs. mild pain vs. severe pain),
Table 1. Patient characteristics

\begin{tabular}{|c|c|c|c|}
\hline \multicolumn{2}{|c|}{ Characteristics } & $n=$ & $\%$ \\
\hline \multicolumn{4}{|l|}{ Age (years) } \\
\hline & Median (range) & \multicolumn{2}{|c|}{$63(30-88)$} \\
\hline \multicolumn{4}{|l|}{ Gender } \\
\hline & Male & 91 & 69 \\
\hline & Female & 41 & 31 \\
\hline \multicolumn{4}{|l|}{ PS } \\
\hline & 0 & 30 & 23 \\
\hline & 1 & 49 & 37 \\
\hline & 2 & 34 & 26 \\
\hline & $\geq 3$ & 19 & 14 \\
\hline \multicolumn{4}{|l|}{ Histology } \\
\hline & Adenocarcinoma & 90 & 68 \\
\hline & Squamous cell carcinoma & 18 & 14 \\
\hline & Small cell carcinoma & 16 & 12 \\
\hline & Large cell carcinoma & 1 & 1 \\
\hline & Other & 7 & 5 \\
\hline \multicolumn{4}{|c|}{ Number of bone metastases } \\
\hline & Solitary & 41 & 31 \\
\hline & Multiple & 91 & 69 \\
\hline \multicolumn{4}{|c|}{ Number of metastatic organs } \\
\hline & 0 & 70 & 53 \\
\hline & 1 & 47 & 36 \\
\hline & $\geq 2$ & 15 & 11 \\
\hline \multicolumn{4}{|l|}{ Metastatic site } \\
\hline & Brain & 34 & \\
\hline & Liver & 23 & \\
\hline & Adrenal gland & 9 & \\
\hline
\end{tabular}

performance status [PS] (0-1 vs. $\geq 2$ ), biological effective dose [BED] ( $\geq 40$ Gy vs. $<40 \mathrm{~Gy}$ ), time to distant metastasis ( $\geq 1$ year vs. $<1$ year), and histology (adenocarcinoma vs. other). In addition, to determine whether or not EGFR-targeted agents influence survival, we evaluated subgroups of patients with adenocarcinoma who were treated with and without EGFRtargeted agents. With regard to the treatment for the primary site, video-assisted thoracic surgery [VATS] was included in the surgery group, whereas stereotactic body radiotherapy and proton therapy were included in the other group.

In cases where patients underwent more than one course of radiotherapy for bone metastases, we classified them depending on the first treatment site. When the spine and other bone metastases were treated at the same time, the patients were classified into the spine group. For the number of bone metastases, the patients with two vertebral metastases were included in the multiple group. The number of metastatic organs was evaluated at the time of starting radiotherapy, and indicated the number of metastatic visceral organ sites other than bone metastasis. The neurological symptoms were divided into three categories. Only patients with numbness were defined as belonging to the numbness group, and those with paresis or paralysis were defined as the paresis group. The degree of 
pain was also divided into three categories based on the use of medication. Mild pain indicated the need for a weak opioid analgesic or nonsteroidal anti-inflammatory drug [NSAID], and severe pain indicated the need for an opioid analgesic. The degree of pain was assessed when radiotherapy was started. The performance status was evaluated according to the Eastern Cooperative Oncology Group [ECOG] criteria at the start of radiotherapy. We used the BED to compare the different radiation schedules. The BED was calculated using following formula, as derived from the linear-quadratic model, assuming an $\alpha / \beta$-ratio of $10 \mathrm{~Gy}$ for tumor cell killing.

$\mathrm{BED}=\mathrm{nd}(1+\mathrm{d} / \alpha / \beta)$

Where $\mathrm{n}=$ fraction number, $\mathrm{d}=$ daily dose, $\mathrm{nd}=$ total dose, $\alpha=$ linear component, $\beta=$ quadratic component, and $\alpha / \beta$-ratio $=$ the dose at which both components are equal. The time to distant metastasis represents the interval between the initial diagnosis of lung cancer and the first detection of any distant metastasis. Pulmonary metastasis and supraclavicular lymphnode metastasis were not included as distant metastasis.

Table 2. Treatment characteristics

\begin{tabular}{|c|c|c|c|}
\hline \multicolumn{2}{|l|}{ Characteristics } & $n=$ & dose \\
\hline \multicolumn{4}{|c|}{ Radiotherapy dose completed (Gy) } \\
\hline \multicolumn{2}{|c|}{ Median } & & 30 \\
\hline \multicolumn{2}{|l|}{ Range } & & $8-60$ \\
\hline \multicolumn{4}{|c|}{ Treatment for primary site } \\
\hline \multicolumn{2}{|c|}{ Surgery } & 32 & \\
\hline \multicolumn{2}{|l|}{ Other } & 100 & \\
\hline & Chemoradiotherapy & 13 & \\
\hline & Radiotherapy alone & 7 & \\
\hline & Stereotatic or Proton ${ }^{*}$ & 2 & \\
\hline & Chemotherapy alone & 63 & \\
\hline & Best supportive care & 15 & \\
\hline \multicolumn{4}{|l|}{ Treatment site } \\
\hline \multicolumn{2}{|l|}{ Spine } & 86 & \\
\hline \multicolumn{2}{|l|}{ Other } & 61 & \\
\hline & Skull & 1 & \\
\hline & Scapula & 3 & \\
\hline & Clavicle & 5 & \\
\hline & Rib & 17 & \\
\hline & Sternum & 1 & \\
\hline & Pelvic bone & 16 & \\
\hline & Extremity bone & 18 & \\
\hline \multicolumn{4}{|c|}{ Administration of EGFR-targeted agents } \\
\hline No & & 86 & \\
\hline \multirow[t]{4}{*}{ Yes } & & 46 & \\
\hline & Gefitinib & 34 & \\
\hline & Erlotinib & 3 & \\
\hline & Gefitinib+Erlotinib & 9 & \\
\hline
\end{tabular}

* One patient was treated with stereotactic radiotherapy and the other with proton therapy EGFR, epidermal growth factor receptor.
When distant metastasis was present at the first examination, the time was indicated to be zero.

Patients were followed until death, and surviving patients were censored at the time of their last follow-up. The survival time was measured from the start of first radiotherapy to bone and the survival rate was calculated using the Kaplan-Meier method. Differences between Kaplan-Meier curves were determined with the log-rank test, and the Cox proportional hazard model was used for the multivariate analysis to estimate the prognostic factors. All analyses were two-sided. The PASW statistics 18.0 software program (SPSS Inc, Chicago, IL) was used for statistical analyses and $\mathrm{p}<0.05$ was considered to be statistically significant.

\section{Results}

The median follow-up period was 5 months (range, 1-52 months). The median survival time was 4.8 months. The overall survival rate was $25 \%$ at 1 year and $15 \%$ at 2 years.

The treatment characteristics are shown in Table 2. Irradiation of bone lesions was performed with 15- or 18-MV linear accelerator beams. The irradiation field included the tumor lesions plus an adequate margin of adjacent normal bone and soft tissue. The majority of patients were treated using parallel opposing fields. The dose was basically prescribed to the center of the planning target volume. Some chemotherapy protocols, most of which were platinum-based regimens, were used in various settings in this study. The administration of EGFRtargeted agents was performed before, after and concurrent to radiotherapy in 19,19 , and 2 patients, respectively. The other 6 patients were administered the agent both before and after radiotherapy.

The outcomes of the univariate analysis are presented in Table 3. Each variable, excluding the treatment site, showed a significant difference. The survival rate was higher for the following subgroups among these variables in the entire population: surgery was better than other treatments for the primary site $(p=0.006)$; solitary metastasis was better than multiple metastases $(p=0.023)$; a PS $0-1$ was better than a PS $\geq 2(p<0.001)$; BED $\geq 40$ Gy was better than $<40$ Gy $(p<0.001)$; the time to distant metastasis $\geq 1$ year was better than $<1$ year $(p=0.006)$; adenocarcinoma was better than other types of histology $(p=0.001)$; no metastatic organ was better than 1 and $\geq 2$ metastatic organs $(p=0.02$ and $<0.001$, respectively); no neurological symptoms and numbness were better than paresis ( $p=0.001$ and $<0.001$, respectively); and no pain was better than mild and severe pain $(p=0.008$ and 0.002 , respectively). The univariate subgroup analysis restricted to patients with adenocarcinoma revealed that patients who were administered EGFR-targeted agents showed a significantly better prognosis $(p=0.005)$.

The results of multivariate analysis are shown in Table 4 . In the multivariate analysis of the entire population, the number of bone metastases, PS, BED, and histology were found to be the independent prognostic factors $(p=0.038,0.006,0.003$ 
Table 3. The results of a univariate analysis of the potential prognostic factors for overall survival after radiotherapy

\begin{tabular}{|c|c|c|c|c|c|c|}
\hline \multirow{2}{*}{ characteristics } & \multicolumn{3}{|c|}{ All patients $(\mathrm{n}=132)$} & \multicolumn{3}{|c|}{ Patients with adenocarcinoma $(\mathrm{n}=90)$} \\
\hline & $n=$ & MST(Mo) & $p=$ & $n=$ & MST(Mo) & $p=$ \\
\hline Treatment for primary site & & & 0.006 & & & 0.025 \\
\hline Surgery & 32 & 15 & & 27 & 17 & \\
\hline Other & 100 & 5 & & 63 & 5 & \\
\hline Treatment site & & & 0.231 & & & 0.169 \\
\hline Spine & 86 & 5 & & 61 & 5 & \\
\hline Other & 46 & 7 & & 29 & 11 & \\
\hline Number of bone metastases & & & 0.023 & & & 0.019 \\
\hline Solitary & 41 & 7 & & 24 & 11 & \\
\hline Multiple & 91 & 5 & & 66 & 6 & \\
\hline Number of metastatic organs & & & 0.003 & & & 0.011 \\
\hline 0 & 70 & 7 & & 51 & 7 & \\
\hline 1 & 47 & 4 & & 31 & 5 & \\
\hline$\geq 2$ & 15 & 3 & & 8 & 3 & \\
\hline Neurological symptoms & & & 0.002 & & & 0.024 \\
\hline No & 93 & 6 & & 67 & 6 & \\
\hline Numbness & 26 & 6 & & 17 & 10 & \\
\hline Paresis & 13 & 3 & & 6 & 2 & \\
\hline Degree of pain & & & 0.003 & & & 0.011 \\
\hline No pain & 10 & 23 & & 8 & * & \\
\hline Mild & 46 & 6 & & 35 & 7 & \\
\hline Severe & 76 & 4 & & 47 & 5 & \\
\hline Performance status & & & $<0.001$ & & & $<0.001$ \\
\hline $0-1$ & 79 & 7 & & 57 & 10 & \\
\hline$\geq 2$ & 53 & 3 & & 33 & 4 & \\
\hline Biological effective dose & & & $<0.001$ & & & $<0.001$ \\
\hline$\geq 40 \mathrm{~Gy}$ & 45 & 12 & & 32 & 22 & \\
\hline$<40 \mathrm{~Gy}$ & 87 & 4 & & 58 & 5 & \\
\hline Time to distant metastasis & & & 0.006 & & & 0.003 \\
\hline$\geq 1$ year & 33 & 13 & & 24 & 23 & \\
\hline$<1$ year & 99 & 5 & & 66 & 5 & \\
\hline Histology & & & 0.001 & & & \\
\hline Adenocarcinoma & 90 & 6 & & & & \\
\hline Other & 42 & 4 & & & & \\
\hline EGFR-targeted agents & & & & & & 0.005 \\
\hline Yes & & & & 44 & 11 & \\
\hline No & & & & 46 & 4 & \\
\hline
\end{tabular}

*, not reached

EGFR, epidermal growth factor receptor.

and 0.014 , respectively). The presence of solitary bone metastasis, $\mathrm{PS}<2, \mathrm{BED} \geq 40 \mathrm{~Gy}$, and adenocarcinoma histology were significantly correlated with better survival. With regard to the survival rate among patients with adenocarcinoma, a multivariate subgroup analysis restricted to patients with adenocarcinoma revealed that the use of EGFR-targeted agents was a significant covariate $(p<0.001)$.

To evaluate the influence of the BED in detail, one additional analysis was performed. The additional analysis comprised a contingency table to assess the relationship between each variable and the number of patients according to the administered BED (table5). The presence of any association between the each factor and the number of patients were evaluated using the two-sided Fisher's exact test. The results showed the administered BED to be associated with some important prognostic factors, such as the treatment of the primary site, the number of metastatic organs, and the performance status. Table 5 includes the MST of each 
Table 4. The results of a multivariate analysis of the potential prognostic factors for overall survival after radiotherapy.

\begin{tabular}{|c|c|c|c|c|c|c|}
\hline \multirow{2}{*}{ Factors } & \multicolumn{3}{|c|}{ All patients } & \multicolumn{3}{|c|}{ Patients with adenocarcinoma } \\
\hline & HR & $95 \% \mathrm{CI}$ & $p=$ & HR & $95 \% \mathrm{CI}$ & $p=$ \\
\hline Treatment for primary site & & & 0.495 & & & 0.188 \\
\hline \multicolumn{7}{|l|}{ Surgery } \\
\hline Other & 1.23 & $0.68-2.57$ & & 1.80 & $0.75-4.29$ & \\
\hline Treatment site & & & 0.850 & & & 0.305 \\
\hline \multicolumn{7}{|l|}{ Spine } \\
\hline Other & 0.96 & $0.62-1.49$ & & 1.38 & $0.75-2.54$ & \\
\hline Number of bone metastases & & & 0.038 & & & 0.110 \\
\hline \multicolumn{7}{|l|}{ Solitary } \\
\hline Multiple & 1.66 & $1.03-2.68$ & & 1.81 & $0.88-3.75$ & \\
\hline Number of metastatic organs & & & 0.561 & & & 0.068 \\
\hline \multicolumn{7}{|l|}{0} \\
\hline 1 & 1.24 & $0.81-1.90$ & 0.321 & 1.87 & $1.01-3.48$ & 0.047 \\
\hline$\geq 2$ & 1.26 & $0.67-2.40$ & 0.475 & 2.13 & $0.87-5.21$ & 0.097 \\
\hline Neurological symptoms & & & 0.751 & & & 0.789 \\
\hline \multicolumn{7}{|l|}{ No } \\
\hline Numbness & 0.94 & $0.55-1.61$ & 0.813 & 0.77 & $0.35-1.68$ & 0.514 \\
\hline Paresis & 1.27 & $0.65-2.48$ & 0.492 & 1.06 & $0.39-2.88$ & 0.903 \\
\hline Degree of pain & & & 0.204 & & & 0.090 \\
\hline \multicolumn{7}{|l|}{ No pain } \\
\hline Mild & 1.88 & $0.71-5.01$ & 0.206 & 2.72 & $0.75-9.87$ & 0.127 \\
\hline Severe & 2.33 & $0.88-6.18$ & 0.090 & 3.90 & $1.07-14.15$ & 0.039 \\
\hline Performance status & & & 0.006 & & & 0.109 \\
\hline \multicolumn{7}{|l|}{$0-1$} \\
\hline$\geq 2$ & 1.86 & $1.19-2.89$ & & 1.57 & $0.90-2.72$ & \\
\hline Biological effective dose & & & 0.003 & & & 0.012 \\
\hline \multicolumn{7}{|l|}{$\geq 40 \mathrm{~Gy}$} \\
\hline$<40 \mathrm{~Gy}$ & 2.148 & $1.30-3.54$ & & 2.42 & $1.21-4.85$ & \\
\hline Time to distant metastasis & & & 0.797 & & & 0.982 \\
\hline \multicolumn{7}{|l|}{$\geq 1$ year } \\
\hline$<1$ year & 1.08 & $0.59-1.99$ & & 1.01 & $0.42-2.42$ & \\
\hline Histology & & & 0.014 & & & \\
\hline \multicolumn{7}{|l|}{ Adenocarcinoma } \\
\hline Other & 1.74 & $1.12-2.70$ & & & & \\
\hline EGFR-targeted agents & & & & & & $<0.001$ \\
\hline \multicolumn{7}{|l|}{ Yes } \\
\hline No & & & & 2.965 & $1.61-5.45$ & \\
\hline
\end{tabular}

EGFR, epidermal growth factor receptor.

subgroup. In some subgroups, such as the time to distant metastasis $\geq 1$ year, or the use of EGFR-targeted agents, patients treated with high-dose radiotherapy were observed to have a prolonged survival.

\section{Discussion}

The bone is the most common site for metastasis in cancer. Bone metastasis causes considerable morbidity, and the prognosis of patients with bone metastasis is in generally poor. Radiotherapy is frequently delivered to such patients to improve or maintain their quality of life [QOL]. In the past, many clinical trials and meta-analyses to identify the optimal dose-fractionation schedule of radiotherapy for bone metastases demonstrated the equivalence of different dosefractionation schedules for the palliation of pain due to bone metastases, and there has been a trend toward administering a single fraction [5-8]. However, even though the rate of pain relief in patients treated with a low total dose was the same those who received a high total dose, it was reported that reir- 
Table 5. Distribution of the number of patients and the MST of each subgroup according to the BED.

\begin{tabular}{|c|c|c|c|c|c|c|c|}
\hline \multirow{2}{*}{ Factors } & \multicolumn{2}{|c|}{$N(\mathrm{MST})$} & \multirow{2}{*}{$P=$} & \multirow{2}{*}{ Factors } & \multicolumn{2}{|c|}{$N(\mathrm{MST})$} & \multirow{2}{*}{$P=$} \\
\hline & $\mathrm{BED}<40$ & $\mathrm{BED} \geq 40$ & & & $\mathrm{BED}<40$ & $\mathrm{BED} \geq 40$ & \\
\hline $\begin{array}{l}\text { Treatment for } \\
\text { primary site }\end{array}$ & & & 0.034 & Degree of pain & & & 0.197 \\
\hline Surgery & $16(4.7)$ & $16(26.3)$ & & No pain & $4(11.0)$ & $6\left(^{*}\right)$ & \\
\hline Other & $71(3.0)$ & $29(6.6)$ & & Mild & $31(4.7)$ & $15(9.4)$ & \\
\hline Treatment site & & & 0.248 & Severe & $52(2.2)$ & $24(7.8)$ & \\
\hline Spine & $60(3.3)$ & $26(12.2)$ & & Performance status & & & 0.009 \\
\hline Other & $27(3.5)$ & $19(9.7)$ & & $0-1$ & $45(5.0)$ & $34(15.0)$ & \\
\hline $\begin{array}{l}\text { Number of bone } \\
\text { metastases }\end{array}$ & & & 0.696 & $\geq 2$ & $42(2.0)$ & $11(5.0)$ & \\
\hline Solitary & $26(3.7)$ & $15(16.3)$ & & Time to distant metastasis & & & 0.139 \\
\hline Multiple & $61(2.9)$ & $30(9.9)$ & & $\geq 1$ year & $18(3.6)$ & $15(28.9)$ & \\
\hline $\begin{array}{l}\text { Number of } \\
\text { metastatic organs }\end{array}$ & & & 0.003 & $<1$ year & $69(3.2)$ & $30(6.2)$ & \\
\hline 0 & $37(5.5)$ & $33(11.4)$ & & Histology & & & 0.695 \\
\hline 1 & $37(3.0)$ & $10(26.2)$ & & Adenocarcinoma & $58(4.4)$ & $32(19.0)$ & \\
\hline$\geq 2$ & $13(2.2)$ & $2(4.0)$ & & Other & $29(2.5)$ & $13(6.7)$ & \\
\hline $\begin{array}{l}\text { Neurological } \\
\text { symptoms }\end{array}$ & & & 0.137 & $\begin{array}{l}\text { EGFR-targeted agents } \\
(\mathrm{n}=90)\end{array}$ & & & 1.000 \\
\hline No & $64(3.7)$ & $29(16.1)$ & & Yes & $28(5.5)$ & $16(27.8)$ & \\
\hline Numbness & $13(3.8)$ & $13(11.4)$ & & No & $30(2.8)$ & $16(4.8)$ & \\
\hline Paresis & $10(2.0)$ & $3(3.5)$ & & & & & \\
\hline
\end{tabular}

MST, median survival time. (months) *, not reached

radiation was needed more frequently in these patients [6-8, 11]. Rose et al. [9] stated that the radiotherapy dose delivered to patients with bone metastases should be determined according to their life expectancy. Indeed, research by Alysa et al. [10] showed that when clinicians prescribe the dose, they place the greatest emphasis on the life expectancy of patient. Therefore, the selection of the total radiation dose is a very important issue to ensure appropriate radiation treatment for bone metastasis.

Past studies of bone metastasis from various sites have shown that the primary site and existence of metastasis to a visceral organ are significant prognostic factors. With regard to the survival rate after radiotherapy for bone metastasis, it was reported that the significant prognostic factors are the PS, number of bone metastases, pain score, and primary site $[5,17]$. However, the prognosis and response to radiotherapy for patients with bone metastases from lung cancer are worse than that of breast cancer and prostate cancer $[2,8,11,18]$. In addition, the effects of systemic therapy on each primary site are different, so it is important to analyze each primary site separately. There have been a few useful reports about the prognostic factors of patients with metastasis from lung cancer. For example, Sugiura et al. [3] studied the prognosis of 118 patients with bone metastases from lung cancer in detail, and disclosed that the tumor histology, site of bone metastasis, and administration of EGFR-targeted agents were independent prognostic factors. It has also been reported that the number of metastatic organs, time to recurrence, adenocarcinoma histology, and local therapy for oligometastatic lesions also affect the prognosis of recurrent lung cancer $[4,19,20]$. There have not been any recent studies focusing on the survival after radiotherapy for bone metastasis from primary lung cancer, so we conducted the present retrospective analysis considering the results of the above studies.

In the present study, all factors other than the treatment site were significant in the univariate analysis, and the number of bone metastases, PS, BED, and histology were identified as independent factors according to a multivariate analysis. In the subgroup analysis for patients with adenocarcinoma performed to estimate the influence of EGFR-targeted agents, the administration of EGFR-targeted agents was found to be a favorable independent prognostic factor. Although these outcomes are in accordance with the above reports, a higher BED was unexpectedly found to be significantly associated with a better survival in the present study.

There have been few studies which demonstrated that the BED affected the survival of patients treated with radiotherapy for bone metastasis. We speculate that the following three explanations may be responsible for this result. First is the possible existence of bias due to the clinicians because of the retrospective nature of this analysis. A higher prescription dose might be selected on the basis of an expectation of a favorable 
prognosis. The second possible explanation is that the use of high dose radiotherapy for oligometastases prevents tumor progression by suppressing the release of tumor-stimulating factors from the bone microenvironment. In the metastatic bone, the microenvironment contains a matrix of tumor growth-stimulating factors, such as transforming growth factor- $\beta$ and insulin-like growth factors, which promote tumor invasion and growth $[21,22]$. These factors stimulate the tumor growth, and therefore bone destruction, thus leading to a release of more of these factors from the bone microenvironment. High dose radiotherapy may improve the survival by reducing these factors. The third explanation is that, under the particular condition examined in this study, intended curative treatment for bone metastasis may affect the survival of patients.

In patients with breast cancer, Punglia et al. [23] described that when effective systemic therapy exists, then local therapy improved the patient survival. Similarly, regarding bone metastases, it was reported that patients treated with high dose radiotherapy who developed oligometastases tended to have a favorable prognosis [24]. Therefore, the strategy used to treat bone metastases may need to be changed as a result of advances in imaging diagnosis and systemic therapy.

Oligometastases is a concept proposed by Hellman [25] that indicates the presence of limited metastases and suggests the existence of an intermediate clinical state between localized disease and widespread disease. It is considered that local treatment for oligometastases improves the overall survival in some patients. In recent years, a favorable prognosis after radiotherapy for the oligometastases with curative intent has been reported. However, majority of the target diseases in these cases are either pulmonary metastases or liver metastases [15, 16]. Regarding oligometastases of bone, the effectiveness of high dose radiotherapy for the metastasis from breast cancer or prostate cancer has been reported, but no reports have been published about the effectiveness of radiotherapy with curative intent for bone metastasis secondary to lung cancer [26, 27]. Murakami et al. [28] performed total en bloc spondylectomy for patients with solitary vertebral bone metastasis from lung cancer without organ metastasis, and the outcome was encouraging. Hirano et al. [29] performed surgery for two case of solitary extremity bone metastasis secondary to lung cancer, and reported that both of them survived over 5 years. Therefore, the presence of oligometastases of bone from lung cancer may become an indication for delivering high dose radiotherapy.

One limitation of the present study is the potential for bias due to its retrospective nature. Indeed, an additional analysis showed the administered BED to be associated with some important prognostic factors. As a result, the patients with a better prognosis tended to have a higher radiation dose. In addition, we were unable to estimate the activity of the primary lesion. If we considered the concept of oligorecurrence proposed by Niibe et al., we might elucidate more clearly the subgroup of patients who should be treated with curative intent [30]. However, in our study, it was difficult to estimate the activity of the primary lesion, because chemotherapy was administered as the principal treatment in many patients. Instead, the time to distant metastasis may indicate the activity of the primary lesion.

The number of bone metastases, the performance status, BED, histology, and use of EGFR-targeted agents were independent prognostic factors. Though we could not clearly demonstrate the efficiency of high-dose radiotherapy due to selection bias, our study nevertheless suggests that high-dose radiotherapy is associated with a better prognosis in combination with other favorable prognostic factors. The present study is therefore considered to provide useful information for performance of further prospective studies.

\section{References}

[1] TSUYA A, KURATA T, TAMURA K, FUKUOKA M. Skeletal metastases in non-small cell lung cancer: A retrospective study. Lung Cancer 2007; 57: 229-232. http: //dx.doi.org/ $\underline{10.1016 / j . l u n g c a n .2007 .03 .013}$

[2] COLEMAN RE. Clinical features of metastatic bone disease and risk of skeletal morbidity. Clin Cancer Res 2006; 12: 6243-6249. http: //dx.doi.org/10.1158/1078-0432.CCR-06-0931

[3] SUGIURA H, YAMADA K, SUGIURA T, HIDA T, MITSUDOMI T. Predictors of survival in patients with bone metastasis of lung cancer. Clin Orthop Relat Res 2009; 466: 729-736. http: //dx.doi.org/10.1007/s11999-007-0051-0

[4] YOSHINO I, YOHENA T, KITAJIMA M, USHIJIMA C, NISHIOKA K et al. Survival of non-small cell lung cancer patients with postoperative recurrence at distant organs. Ann Thorac Cardiovasc Surg 2001; 7: 204-209.

[5] NIEWALD M, TKOCZ HJ, ABEL U, SCHEIB T, WALTER $\mathrm{K}$ et al. Rapid course radiation therapy vs. more standard treatment: a randomized trial for bone metastases. Int J Radiat Oncol Biol Phys 1996; 36: 1085-1089. http: //dx.doi. org/10.1016/S0360-3016(96)00388-4

[6] STEENLAND E, LEER JW, VAN HOUWELINGEN H, POST WJ, VAN DEN HOUT WB et al. The effect of a single fraction compared to multiple fraction on painful bone metastases: a global analysis of the Dutch Bone Metastasis Study. Radiother Oncol 1999; 52: 101-109. http: //dx.doi.org/10.1016/S01678140(99)00110-3

[7] WU JS, WONG R, JOHNSTON M, BEZJAK A, WHELAN T. Meta-analysis of dose-fractionation radiotherapy trials for the palliation of painful bone metastases. Int J Radiat Oncol Biol Phys 2003; 55: 594-605. http: //dx.doi.org/10.1016/S03603016(02)04147-0

[8] VAN DER LINDEN YM, STEENLAND E, VAN HOUWELINGEN HC, POST WJ, OEI B et al. Patients with a favourable prognosis are equally palliated with single and multiple fraction radiotherapy: results on survival in the Dutch Bone Metastasis Study. Radiother Oncol 2006; 78: 245-253. http: //dx.doi.org/10.1016/j.radonc.2006.02.007

[9] ROSE CM, KAGAN AR. The final report of the expert panel for the radiation oncology bone metastasis work group of the American college of radiology. Int J Radiat Oncol Biol 
Phys 1998; 40: 1117-1124. http: //dx.doi.org/10.1016/S0360$\underline{3016(97) 00952-8}$

[10] FAIRCHILD A, BARNES E, GHOSH S, BEN-JOSEF E, ROOS D et al. International patterns of practice in palliative radiotherapy for painful bone metastases: evidence-based practice? Int J Radiat Oncol Biol Phys 2009; 75: 1501-1510. http: //dx.doi.org/10.1016/j.ijrobp.2008.12.084

[11] ARCANGELI G, GIOVINAZZO G, SARACINO B, D'ANGELO L, GIANNARELLI D et al. Radiation therapy in the management of symptomatic bone metastases: the effect of total dose and histology on pain relief and response duration. Int J Radiat Oncol Biol Phys 1998; 42: 1119-1126. http: //dx.doi.org/10.1016/S0360-3016(98)00264-8

[12] CAPPUZZO F, CIULEANU T, STELMAKH L, CICENAS S, SZCZESNA A et al. Erlotinib as maintenance treatment in advanced non-small-cell lung cancer: a multicentre, randomised, placebo-controlled phase 3 study. Lancet Oncol 2010; 11: 521-529. http: //dx.doi.org/10.1016/S1470-2045(10)70112-1

[13] SHEPHERD FA, RODRIGUES PEREIRA J, CIULEANU T, TAN EH, HIRSH V et al. Erlotinib in previously treated nonsmall-cell lung cancer. N Engl J Med 2005; 353: 123-132. http: //dx.doi.org/10.1056/NEJMoa050753

[14] THATCHER N, CHANG A, PARIKH P, RODRIGUES PEREIRA J, CIULEANU T et al. Gefitinib plus best supportive care in previously treated patients with refractory advanced non-small-cell lung cancer: results from a randomised, placebo-controlled, multicentre study. Lancet 2005; 366: 1527-1537. http: //dx.doi.org/10.1016/S0140-6736(05)67625-8

[15] MILANO MT, KATZ AW, SCHELL MC, PHILIP A, OKUNIEFF P. Descriptive analysis of oligometastatic lesions treated with curative-intent stereotactic body radiotherapy. Int J Radiat Oncol Biol Phys 2008; 72: 1516-1522. http: //dx.doi. org/10.1016/j.ijrobp.2008.03.044

[16] MACDERMED DM, WEICHSELBAUM RR, SALAMA JK. A rationale for the targeted treatment of oligometastases with radiotherapy. J Surg Oncol 2008; 98: 202-206. http: //dx.doi. org/10.1002/jso.21102

[17] TONG D, GILLICK L, HENDRICKSON FR. The palliation of symptomatic osseous metastases: final results of the Study by the Radiation Therapy Oncology Group. Cancer 1982; 50: 893-899. http: //dx.doi.org/10.1002/1097-0142(19820901)50: 5<893: : AID-CNCR2820500515>3.0.CO;2-Y

[18] COLEMAN RE. Skeletal complications of malignancy. Cancer 1997; 80: 1588-1594. http: //dx.doi.org/10.1002/(SICI)10970142(19971015)80: 8+<1588: : AID-CNCR9>3.0.CO;2-G

[19] OH Y, TAYLOR S, BEKELE BN, DEBNAM JM, ALLEN PK et al. Number of metastatic sites is a strong predictor of survival in patients with nonsmall cell lung cancer with or without brain metastases. Cancer 2009; 115: 2930-2938. http: //dx.doi. org/10.1002/cncr.24333

[20] YANO T, HARO A, YOSHIDA T, MORODOMI Y, ITO K. Prognostic impact of local treatment against postoperative oligometastases in non-small cell lung cancer. J Surg Oncol 2010; 102: 852-855. http: //dx.doi.org/10.1002/jso.21750

[21] ROODMAN GD. Mechanisms of bone metastasis. N Engl J Med 2004; 350: 1655-1664. http: //dx.doi.org/10.1056/ NEJMra030831

[22] KINGSLEY LA, FOURNIER PG, CHIRGWIN JM, GUISE TA. Molecular biology of bone metastasis. Mol Cancer Ther 2007; 6: 2609-2617.

[23] PUNGLIA RS, MORROW M, WINER EP, HARRIS JR. Local therapy and survival in breast cancer. N Engl J Med 2007; 356: 2399-2405. http: //dx.doi.org/10.1056/NEJMra065241

[24] RADES D, VENINGA T, STALPERS LJ, BASIC H, RUDAT $\mathrm{V}$ et al. Outcome after radiotherapy alone for metastatic spinal cord compression in patients with oligometastases. J Clin Oncol 2007; 25: 50-56. http: //dx.doi.org/10.1200/ LCO.2006.08.7155

[25] HELLMAN S, WEICHSELBAUM RR. Oligometastases. J Clin Oncol 1995; 13: 8-10.

[26] SINGH D, YIWS, BRASACCHIO RA, MUHS AG, SMUDZIN T. Is there a favorable subset of patients with prostate cancer who develop oligometastases? Int J Radiat Oncol Biol Phys 2004; 58: 3-10. http: //dx.doi.org/10.1016/S03603016(03)01442-1

[27] NIIBE Y, KURANAMI M, MATSUNAGA K, TAKAYA M, KAKITA $S$ et al. Value of high-dose radiation therapy for isolated osseous metastasis in breast cancer in terms of oligorecurrence. Anticancer Res 2008; 28: 3929-3931.

[28] MURAKAMI H, KAWAHARA N, DEMURA S, KATO S, YOSHIOKA $\mathrm{K}$ et al. Total en bloc spondylectomy for lung cancer metastasis to the spine. J Neurosurg Spine 2010; 13: 414-417. http: //dx.doi.org/10.3171/2010.4.SPINE09365

[29] HIRANO Y, ODA M, TSUNEZUKA Y, ISHIKAWA N, WATANABE G. Long-term survival cases of lung cancer presented as solitary bone metastasis. Ann Thorac Cardiovasc Surg 2005; 11: 401-404.

[30] NIIBE Y, KENJO M, KAZUMOTO T, MICHIMOTO K, TAKAYAMA $M$ et al. Multi-institutional study of radiation therapy for isolated para-aortic lymph node recurrence in uterine cervical carcinoma: 84 subjects of a population of more than 5,000. Int J Radiat Oncol Biol Phys 2006; 66: 1366-1369. http: //dx.doi.org/10.1016/ j.ijrobp.2006.07.1384 